\title{
Formation and destruction processes of upper Sinian oil-gas pools in the Dingshan-Lintanchang structural belt, southeast Sichuan Basin, China
}

\author{
Liu Shugen*, Zhang Zhijing, Huang Wenming, Wang Guozhi, Sun Wei, \\ Xu Guosheng, Yuan Haifeng, Zhang Changjun and Deng Bin
}

State Key Laboratory of Oil and Gas Reservoir Geology and Exploitation, Chengdu University of Technology, Sichuan 610059, China

(C) China University of Petroleum (Beijing) and Springer-Verlag Berlin Heidelberg 2010

\begin{abstract}
The lower Cambrian Niutitang Formation hydrocarbon source rocks at the DingshanLintanchang structure in the southeast Sichuan Basin were of medium-good quality with two excellent hydrocarbon-generating centers developed in the periphery areas, with a possibility of forming a medium to large-sized oil-gas field. Good reservoir rocks were the upper Sinian (Dengying Formation) dolomites. The mudstone in the lower Cambrian Niutitang Formation with a good sealing capacity was the cap rock. The widely occurring bitumen in the Dengying Formation indicates that a paleo oil pool was once formed in the study area. The first stage of paleo oil pool formation was maturation of the lower Cambrian source rocks during the late Ordovician. Hydrocarbon generation from the lower Cambrian source rocks stopped due to the Devonian-Carboniferous uplifting. The lower Cambrian source rocks then restarted generation of large quantities of hydrocarbons after deposition of the middle Permian sediments. This was the second stage of the paleo oil pool formation. The oil in the paleo oil pool began to crack during the late Triassic and a paleo gas pool was formed. This paleo gas pool was destroyed during the Yanshan-Himalayan folding, uplifting and denudation. Bitumen can be widely seen in the Dengying Formation in wells and outcrops in the Sichuan Basin and its periphery areas. This provides strong evidence that the Dengying Formation in the Sichuan Basin and its periphery areas was once an ultra-large structural-lithologic oil-gas field, which was damaged during the Yanshan-Himalayan period.
\end{abstract}

Key words: Sinian, oil-gas pool, Dingshan-Lintanchang structural belt, Sichuan Basin

\section{Introduction}

The Sichuan Basin is one of the most important oil-gas bearing superimposed basins in south China. The oldest sedimentary strata are upper Sinian (Dengying Formation). The Dengying Formation is one of the most significant highquality reservoirs and gas-bearing horizons in the Sichuan Basin. The Weiyuan gas field, discovered in 1964, was the first large and medium-sized natural gas field found in the Sichuan Basin with proven natural gas reserves of $408 \times 10^{8}$ $\mathrm{m}^{3}$. The major pay zone consisted primarily of Dengying Formation carbonate rocks (Sun et al, 2009). Although exploration and research have been carried out for over 50 years in the Dengying Formation in the Sichuan Basin, no other similar-sized natural gas fields have been found in this formation. It appears that the controlling factors of preservation and distribution of gas and oil in the upper

*Corresponding author. email: 1sg@cdut.edu.cn

Received September 7, 2009
Sinian are not yet fully understood.

The southeastern area of the Sichuan Basin is part of the eastern steep structural belt and the southern gentle structural belt (Fig. 1). Currently, this area is ideal for research on accumulation and formation of upper Sinian oil and gas pools in the Sichuan Basin due to several factors: (1) Abundant information is available as Sinopec has conducted extensive exploration and seismic prospecting in this area in recent years. The upper Sinian was the target stratum in the Dingshan 1 Well and Lin 1 Well, but no economic gas accumulation was found; (2) Core is available from wells drilled through the Dengying Formation; (3) The outcrops of the upper Sinian in the area are suitable for comprehensive study of the surface and subsurface geology.

The study area is located at the southeastern edge of the Sichuan Basin and at the northern slope of the Central Guizhou Uplift. Outcropping strata in the study area are mainly Palaeozoic, while those in the Sichuan Basin are mainly Cretaceous and Jurassic (Fig. 1). The study of the formation of oil and gas pools in the upper Sinian in this 
area is of great importance for petroleum exploration in the Sichuan Basin and evaluation of the upper Sinian oil and gas exploration potential of the central Guizhou area. Based on comprehensive research on geology, geochemistry, geophysics, and surface and subsurface geology, we not only present the petroleum accumulation conditions and the processes of formation and destruction of the upper Sinian petroleum pool in the Dingshan-Lintanchang structural belt in the southeast Sichuan Basin, but also we discuss the characteristics of the upper Sinian paleo oil-gas reservoirs in the Sichuan Basin.

\section{Regional background}

The Dingshan-Lintanchang northeast structural belt belongs to the transitional zone between the southeastern edge of the Sichuan Basin and the western edge of the Xuefeng Mountain Uplift. This structural belt is the front of the Loushanguan trough-like fold belt, with its eastern area stretching to the Nanchuan-Zunyi major fault and western area stretching to the gentle fold area in the southern Sichuan Basin, limited by the Xingwen-Gulin hidden fault. The Dingshan and Lintanchang structures are two secondary anticlines on the western flank of the Sangmuchang composite anticline (Fig. 1). Sedimentary strata outcropping in this area are from the upper Sinian to the Cretaceous, with the upper Silurian, Devonian and Carboniferous absent due to the Caledonian movement. However, the upper Sinian strata can be found only on the axis of the Sangmuchang composite anticline (in the Heba-Runnan region) in an area of about $10 \mathrm{~km}^{2}$ (Fig. 1). Petroleum exploration revealed that the Dengying Formation is about 1,200 m thick (Dingshan 1 Well) with the top at a depth of 2,500-3,500 m. The Sinian is unconformably overlain by lower Cambrian because of the Tongwan movement. Two major fault systems, namely, northeast-trending Sangmuchang and nearly north-south trending Nanchuan-Zunyi faults are developed. In addition, a few northwest-trending faults can be found (Fig. 1).

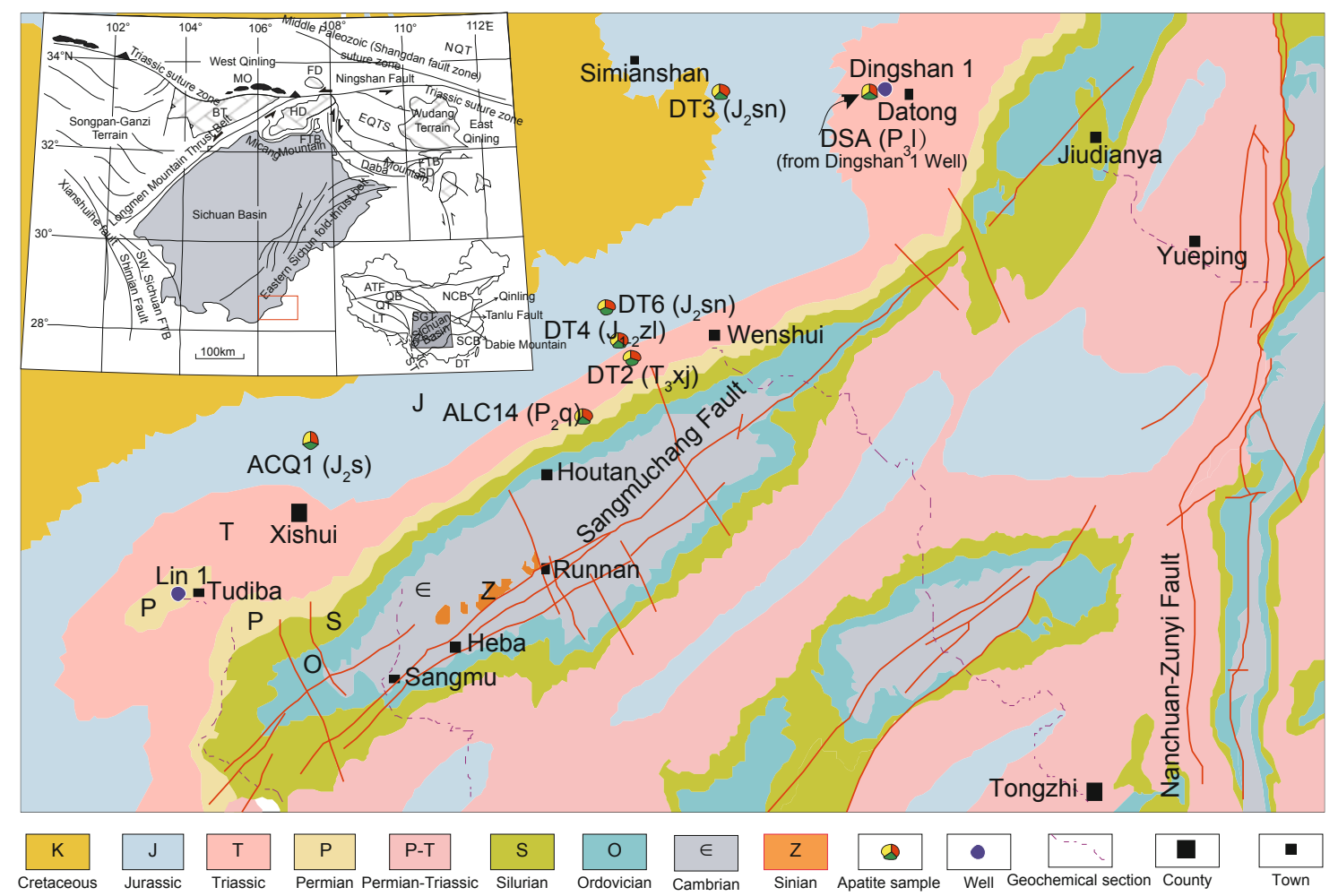

Fig. 1 Simplified geological map of the study area

NCB: North China block, SCB: South China block, SGT: Songpan-Ganzi terrain, QB: Qaidam Basin, QT: Qiangtang terrain, LT: Lhasa terrain, DT: Southeast Asia terrain, ICT: Indochina terrain, ST: Simao terrain, ATF: Altyn Tagh Fault, NQT: North Qinling terrain, EQTS: East Qinling thrust system, BT: Bikou terrain, FD: Foping dome, SD: Shennongjia dome, HD: Hannan dome, FTB: fold-thrust belt, MO: Mianlüe ophiolite, AO: Anyemaqen ophiolite. Modified from Meng et al (2005)

\section{Source, reservoir and cap rocks}

\subsection{Lower Cambrian source rocks}

Abundant bitumen is present in the Dengying Formation in the Sichuan Basin and its periphery areas. It was sourced mainly from the lower Cambrian argillaceous rocks (Dai,
2003).

GC-MS analysis showed that there is adamantane in the upper Sinian bitumen with minor characteristics of waterwashing oxidation, which indicates that the reservoir bitumen in the Dengying Formation was formed by the pyrolysis of crude oil.

The lower Cambrian argillaceous rocks in the Sichuan 
Basin are mainly distributed in the Yibin-Luzhou area (Sichuan Province), western Hunan and Hubei Provinces and Nanjiang-Ningqiang areas, with a thickness of 200-300 m. Two centers of hydrocarbon generation in the lower Cambrian source rocks exist in the Yibin-Luzhou and west Hunan-west Hubei areas with a hydrocarbon generation capacity of (150$200) \times 10^{8} \mathrm{~m}^{3} / \mathrm{km}^{2}$. In the study area, the medium-good quality source rocks in the lower Cambrian Niutitang Formation are 0-20 m thick (Liang et al, 2008). In the Dingshan 1 Well, the black carbonaceous mudstone at the bottom of the lower Cambrian Niutitang Formation is 13 m thick. The TOC in 29 samples was $0.3 \%-3.9 \%$, with $25 \%$ of the samples having TOC higher than $0.5 \%$ and the average is $0.7 \%$. Kerogen is of type $\mathrm{II}_{1}$, and is a medium quality hydrocarbon source (Qin et al, 2005; 2006; 2009). In the Lin 1 Well, the dark mudstone of the Niutitang Formation is $158 \mathrm{~m}$ thick, with a kerogen type of $\mathrm{I}_{-} \mathrm{II}_{1}$. The mudstone is dark gray except for the grayish-black areas at the bottom. The TOC of eight samples was $0.07 \%-0.95 \%$, and that of two samples between $2,462.13 \mathrm{~m}$ and $2,468.43 \mathrm{~m}$ was only $0.07 \%$ and $0.08 \%$ respectively. Thus, it is evident that the upper part of the Niutitang Formation was a fairly poor source rock and had almost no hydrocarbon generating capacity, but the lower part was relatively good hydrocarbon source rock, with its organic carbon content higher than $0.55 \%$.

The lower Cambrian source rocks in the southeast Sichuan Basin were of medium-good quality and comprised beds only 13-20 m thick. However, two high-quality hydrocarbon generation centers developed in the periphery area. Being an important area for oil and gas migration and accumulation, this study area contained petroleum sources needed for the formation of a large or medium-sized oil-gas field (Liu et al, 2006).

\subsection{Sinian reservoir rocks}

Reservoir rocks in the Dengying Formation are mainly algal boundstones, and doloarenite (Ao et al, 2006). Porous dolomites developed near the unconformities between the upper Sinian and the Cambrian. The samples from the Lin 1 Well, Dingshan 1 Well and the outcrops showed that the Dengying Formation reservoir rocks were tight with the porosity of 1\%-2\% (Liu et al, 2007; 2008b). The reservoir space is mainly intercrystalline (dissolved) pores, vugs and/or fractures.

(1) Pores and vugs formed by fresh water dissolution

The $\delta^{13} \mathrm{C}$ and $\delta^{18} \mathrm{O}$ isotopic values of carbonate rocks under the unconformity were suddenly lowered by the interaction between the fresh water and rocks, leading to abrupt change of carbon and oxygen isotopes (Cander, 1995; Dickson and Saller, 1995; Wagner et al, 1995). The carbon and oxygen isotopes of carbonate rocks and fillings of the pores and vugs below the unconformity between the upper Sinian and the lower Cambrian in the Dingshan 1 Well showed a significant decline and negative bias, indicating palaeo-karstification. The karstification reached a depth of around $150 \mathrm{~m}$ below the unconformity surface. A large quantity of dissolution pores, vugs and karst breccia can be found in the upper
Sinian cores of the Dingshan 1 Well and Lin 1 Well (Fig. 2(a)). Some of them could represent dissolution originated vugs subsequently partly infilled. The petrological characteristics of the fillings (e.g. crusty structure developing at the edge) and the geochemical characteristics of carbon, oxygen and strontium isotopes showed that the formation mechanism was freshwater karstification. The density of vugs and fractures in the Dingshan 1 Well was $0.15-8$ per meter and 0.21 per meter respectively, with most of the vugs being medium and small in size. The dissolved vugs and fractures in the study area did not develop as much as those in the palaeo-uplift areas in the central Sichuan Basin (Liu et al, 2008a).

(2) Pores and vugs dissolved by acid fluids

Carbonate rocks in the study area have been strongly corroded by acidic fluids (Barth and Bjørlykke, 1993), indicated by dissolution along stylolite seams (Fig. 2(b)). Dissolution along fractures and algal laminae (Fig. 2(c)) as well as pores were found in cores from the Lin 1 Well, with a residual plane porosity of 3\% (Fig. 2(d)). Thin-section observation of the rocks showed corrosion and filling of late acid silica along stylolites in the upper Sinian rocks.

(3) Vugs dissolved by hydrothermal fluids

Silica rocks, zebra dolomite (Fig. 2(e), (f) and (g)), lead zinc ore, fluorite and barite are present in the upper Sinian of the Dingshan-Lintanchang structural belt in the southeast Sichuan Basin. Their presence indicates that the Dengying Formation has been altered by hydrothermal fluids, and the porosity is up to $20 \%$ (Fig. 2(e)), especially at the anticline axis area of Sangmu Town. At the well cores near the unconformity between the upper Sinian and the lower Cambrian in the Lin 1 Well, isolated pores developed inside the white coarse-grain dolomites with the vug porosity up to $3 \%$. Moreover, intercrystalline pores also developed in saddle dolomites which now contain bitumen $5 \%$ of the rock (Fig. 2(h)), which indicates that the Dengying Formation had sufficient porosity during the oil-gas charging process.

Therefore, deep-burial acid fluid dissolution and hydrothermal dissolution formed a good-quality reservoir on the basis of early freshwater karstic pores in the Dengying Formation.

\subsection{Cap rocks}

Apart from the mudstones in the lower Cambrian Niutitang Formation, as direct cap rocks for the Dengying Formation, gypsum, gypsum dolomite, or limestone in the middle-lower Cambrian had high sealing capacity.

(1) Argillaceous cap rocks

Distributed over the whole study area, lower Cambrian argillaceous cap rocks such as shale and sandy mudstone are interlayered with limestone. For example, the lower Cambrian in the profiles at Houtan, Xishui County, has a total thickness of $423 \mathrm{~m}$, among which argillaceous rocks are 213 $\mathrm{m}$ thick, accounting for $50 \%$ of the strata. The total thickness of argillaceous limestone and argillaceous dolomite is $32 \mathrm{~m}$, accounting for $7.6 \%$. Therefore, the total thickness of the cap rocks reached up to $245 \mathrm{~m}$, accounting for $58 \%$ of the strata. 

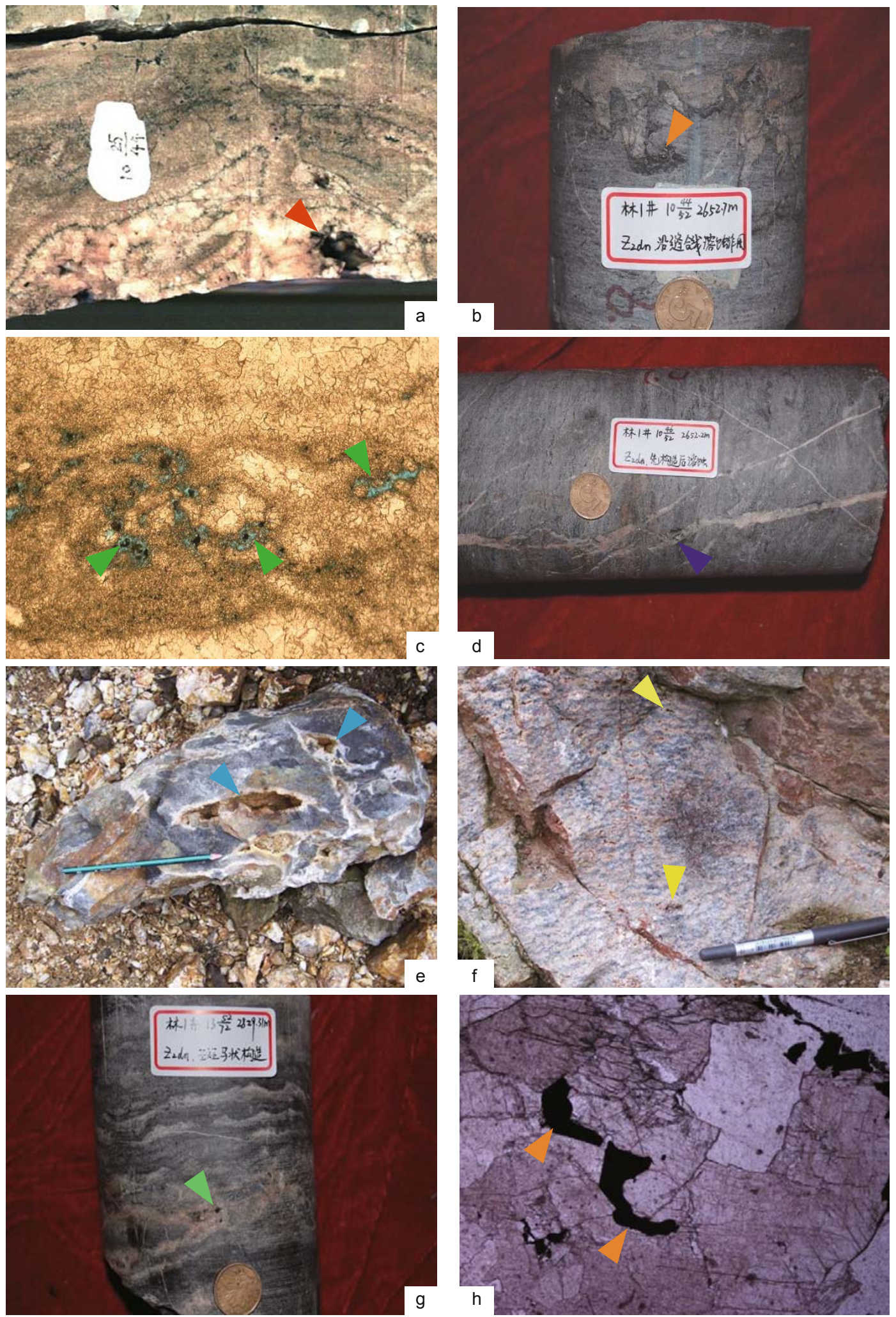

Fig. 2 Reservoir rock photographs of the upper Sinian Dengying Formation in the study area

(a) Dissolution pores by meteoric water (arrow). The pores are filled with botryoidal crust and fine-crystalline dolomite in supergene stage, and coarse crystalline dolomite, quartz, and bitumen in the burial stage. Residual porosity is about 5\%. Upper Sinian Dengying Formation, Dingshan 1 Well. (b) Burial dissolution along the stylolite. Residual porosity is about 3\%. Upper Sinian Dengying Formation, Lin 1 Well. (c) Algae doloarenite. Dissolution pores developed in the algae-rich laminae by deep burial dissolution. Residual porosity was about 5\%. Upper Sinian Dengying Formation. Lin 1 Well $(2,625.5 \mathrm{~m})$. (d) Corrosion and filling-up of fracture. Residual porosity is about 3\%. Upper Sinian Dengying Formation, Lin 1 Well (2,652.2 m). (e) Pores by hydrothermal dissolution. Residual porosity was about 20\%. Upper Sinian Dengying Formation, Heba, Xishui (f) Zebra dolomite at the top of the Sinian. Pores by hydrothermal dissolution developed inside. Residual porosity is about $8 \%-10 \%$. Heba, Xishui. (g) Zebra dolomite and pores formed by hydrothermal dissolution. Residual porosity is about 3\%. Upper Sinian Dengying Formation, Lin 1 Well. (h) Bitumen in intercrystalline pores of saddle dolomite. Bitumen content is $5 \%$. Upper Sinian Dengying Formation, Lin 1 Well. 
The maximum thickness of a single layer of argillaceous cap rocks in the lower Cambrian Niutitang Formation in the Dingshan 1 Well and Lin 1 Well is $28.5 \mathrm{~m}$. The general thickness of a single layer is $6.0 \mathrm{~m}$ and the average total thickness is $146 \mathrm{~m}$. The breakthrough pressure of these rocks is $77-87 \mathrm{MPa}$.

Therefore, it can be concluded that the lower Cambrian argillaceous rocks can be classified as high-quality regional cap rocks for the upper Sinian.

(2) Gypsum cap rocks

Gypsum which is considered to be an ideal cap rock is widely developed during the middle-lower Cambrian. The Cambrian gypsum-salt strata mainly occur in the middle Cambrian Shilengshui Formation and lower Cambrian Qingxudong Formation, with a regional thickness of 2-46 m. Basically, gypsum rocks in the Dingshan 1 Well are evenly developed in the Qingxudong and Shilengshui formations.
The pure gypsum rocks (white and gray-white) are $29 \mathrm{~m}$ thick, and gray-white gypsiferous dolomite (limestone) is 10 $\mathrm{m}$ thick in the well. The gypsum in the Lin 1 Well is mainly located at the top of the Qingxudong Formation, with a thickness of $13 \mathrm{~m}$. Gypsum is overlain and underlain by graywhite gypsiferous dolomites. Gypsum rock in the middle Cambrian Shilengshui Formation is $27 \mathrm{~m}$ thick, and in the Qingxudong Formation is $17 \mathrm{~m}$ thick. Thus, the middle-lower Cambrian gypsum cap rocks provide excellent sealing for the underlying Dengying Formation.

\section{Characteristics of structural traps}

The Dingshan-Lintanchang structural traps were primarily formed during Cambrian sedimentation, with inheritance at later stages. However, the sizes and widths of traps changed greatly in different periods and the structural high had a degree of migration as well (Table 1, Fig. 3).

Table 1 Contrast of trap elements at the top surface of the Sinian between the Dingshan Structure and the Lintanchang Structure

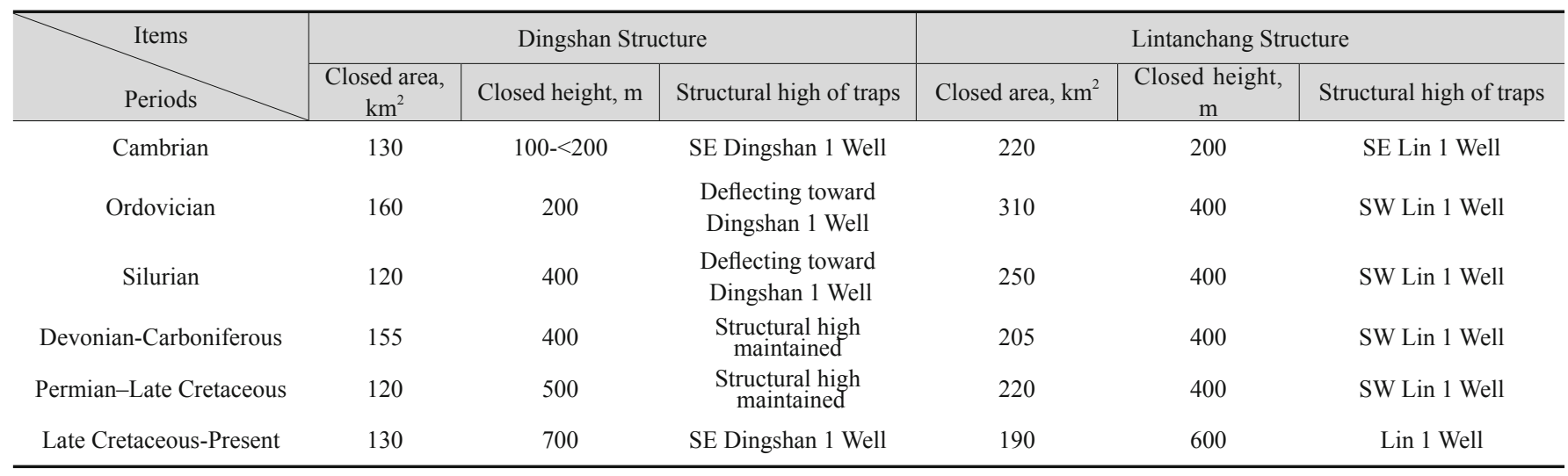

5 Scale and formation process of the Sinian paleo oil pool

\subsection{Scale of the Sinian paleo pool and its oil-cracking gas}

Microscopically, the bitumen content in the cores of the Dengying Formation in the Dingshan 1 Well is $0.5 \%-5.6 \%$ (Fig. 4). On average the thin sections contained 3\% bitumen with only a few reaching up to $9 \%$ bitumen. The bitumen content of thin sections from near the unconformity between the Sinian and the Cambrian is relatively high and gradually declines below the unconformity. However, the bitumen content increased in some upper Sinian intervals in the Dingshan 1 Well. The average bitumen content at the depth of $3,573.9$ to $3,604.2 \mathrm{~m}$ is $0.17 \%$. However, the bitumen content is up to $0.5 \%$ at the deeper level of $3,650.61 \mathrm{~m}$ in the well (Sun et al, 2010). The drilling depth of the Dengying Formation in the Dingshan 1 Well was 3,492-4,610 m (without reaching the bottom of the formation). Bitumen occurred continuously from the top surface to a depth of $4,070 \mathrm{~m}$, but below this depth no bitumen could be found. Therefore, this may indicate that the oil-water interface in the upper Sinian paleo oil pool was at a depth of $4,070 \mathrm{~m}$ and its oil column height was about $500 \mathrm{~m}$ (Fig. 4).
The subsurface depth of the Dengying Formation in the Lin 1 Well is $2,585 \mathrm{~m}$ to $2,910 \mathrm{~m}$ with a thickness of only $325 \mathrm{~m}$ (without reaching the bottom of the formation). The average content of bitumen in the thin sections from the upper Sinian cuttings is $2.2 \%$. Microscopically, the bitumen content in the thin sections from the cores is between $0.1 \%-8 \% .50 \%$ of all thin sections from cores of the Dengying Formation in the Lin 1 Well contain bitumen. The bitumen distribution is discontinuous, most is found within $100 \mathrm{~m}$ under the top of the unconformity. Below the depth of $2,827 \mathrm{~m}$, no large quantities of bitumen have been found. Therefore, the depth of $2,827 \mathrm{~m}$ can be identified as the oil-water interface and the oil column height of the Sinian paleo oil pool in the Lin 1 Well was at least $242 \mathrm{~m}$ (Fig. 4).

The peak of hydrocarbon generation from the lower Cambrian Niutitang Formation source rocks was during the Permian, which was the main period for the formation of paleo oil pools in the study area. At the end of the Permian, the Lin 1 Well was actually not the structural high of the Lintanchang structural trap, but a local high point on the slope (Fig. 3(e)). With the palaeo-structure reconstruction of the top surface of the upper Sinian after the middle Permian sedimentation, it could be inferred that the paleo oil column height in the Lintanchang structural trap was about $350 \mathrm{~m}$, with an oil-bearing area of $220 \mathrm{~km}^{2}$ (Fig. 3(e)). 

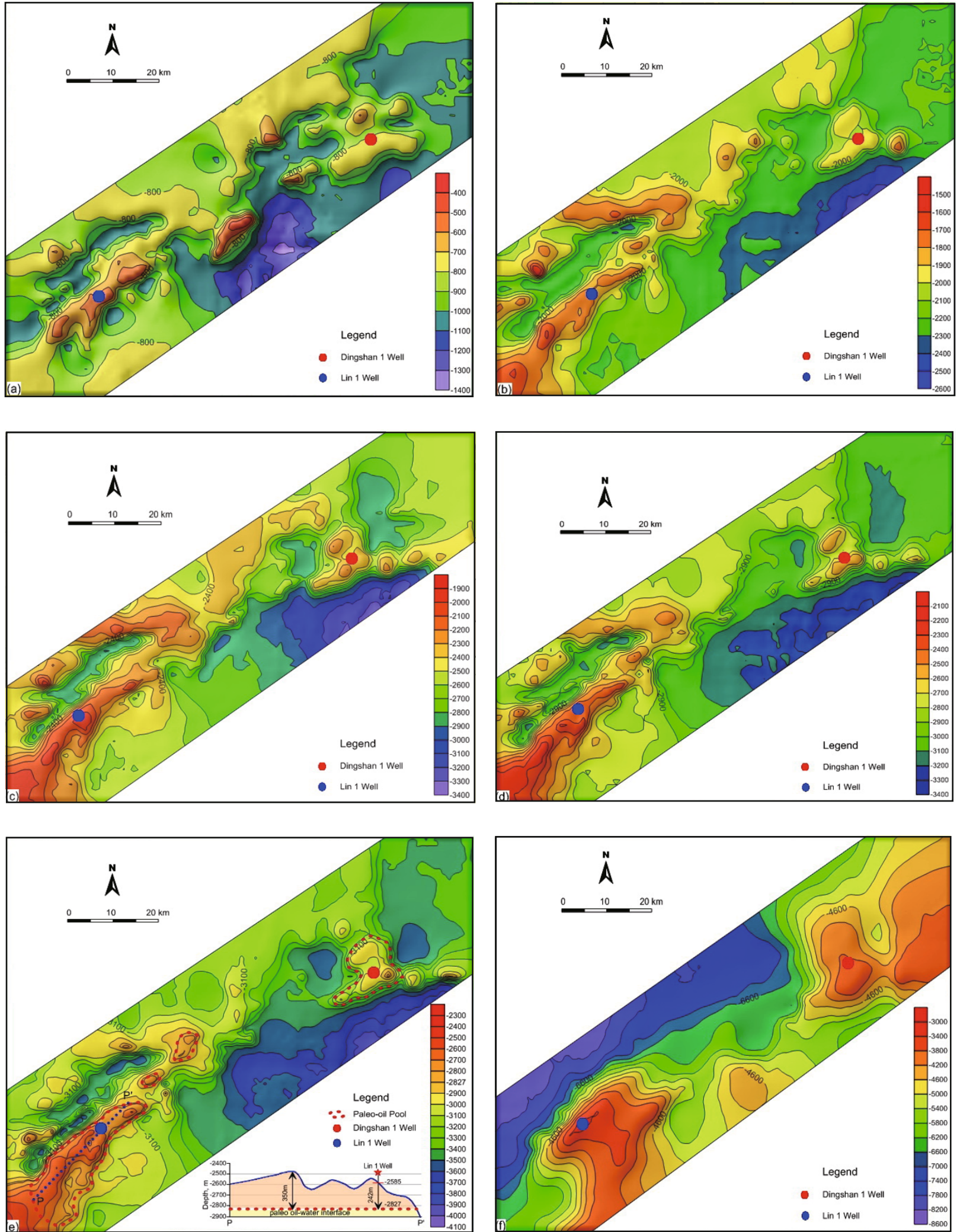

Fig. 3 Evolution of the Dingshan-Lintanchang structural belt in the southeast Sichuan Basin

(a) Structural map of the top surface of the Sinian after the Lower-Cambrian sedimentation. (b) Structural map of the top surface of the Sinian after the Ordovician sedimentation. (c) Structural map of the top surface of the Sinian after the Lower-Silurian sedimentation. (d) Structural map of the top surface of the Sinian after the Silurian sedimentation. (e) Structural map of the top surface of the Sinian after the MiddlePermian sedimentation. (f) Structural map of top surface of the Sinian at present.

Based on the content of the reservoir bitumen in the Dengying Formation in the two exploration wells and the characteristics of the paleo-structural traps, oil reserves in the
Lintanchang and Dingshan structural paleo-traps could be calculated as $6.7 \times 10^{8} \mathrm{t}$ and $1.9 \times 10^{8} \mathrm{t}$ respectively using the equation: 


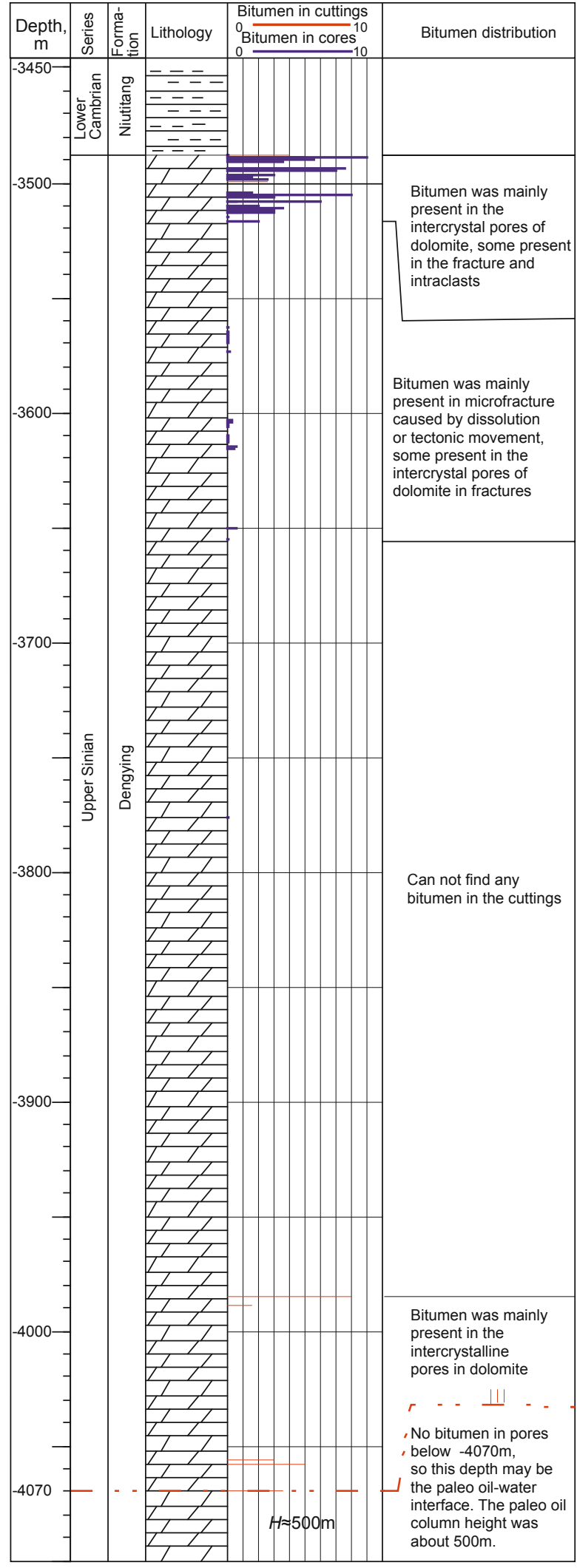

$Q=A \times H \times \square \times S_{\mathrm{o}} \times \rho / B o i(\mathrm{Wu}, 2005)$ (See Table 2 for parameter determination)

Therefore, in the Dingshan-Lintanchang structural belt, there was a paleo oil pool with the petroleum reserve of $8.6 \times 10^{8} \mathrm{t}\left(6.7 \times 10^{8} \mathrm{t}+1.9 \times 10^{8} \mathrm{t}\right)$.

The average gas cracked from one ton of oil is about 620

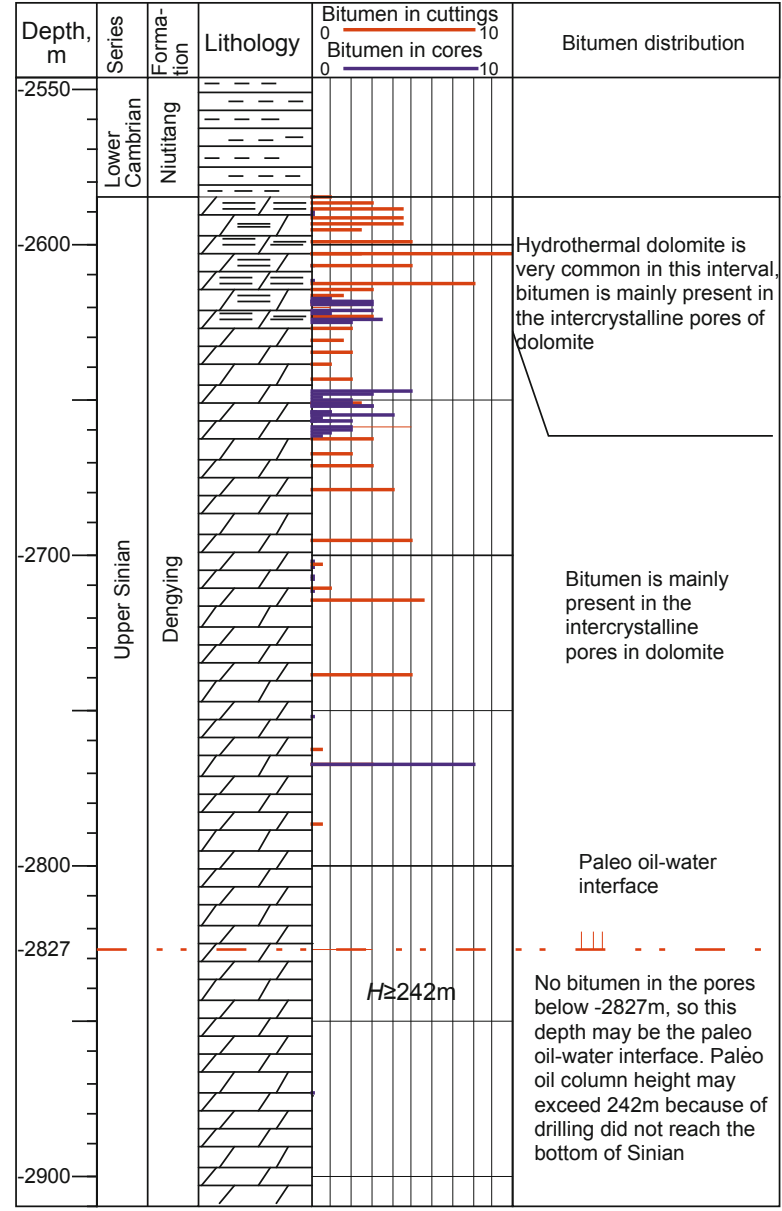

Fig. 4 Vertical bitumen content profiles in the upper Sinian Dengying Formation in Dingshan 1 well and Lin 1 Well (Left: Dingshan 1 Well; Right: Lin 1 Well)

$\mathrm{m}^{3}$ (Barker, 1990; Lu et al, 2002). The amount of gas from the cracked crude oil in the Lintanchang and Dingshan structures can be calculated as $G_{1}=Q_{1} \times 620 \mathrm{~m}^{3} / \mathrm{t}=6.7 \times 10^{8} \mathrm{t} \times 620 \mathrm{~m}^{3} / \mathrm{t}$ $=4154 \times 10^{8} \mathrm{~m}^{3}$ and $G_{2}=Q_{2} \times 620 \mathrm{~m}^{3} / \mathrm{t}=1.9 \times 10^{8} \mathrm{t} \times 620 \mathrm{~m}^{3} / \mathrm{t}$ $=1178 \times 10^{8} \mathrm{~m}^{3}$ respectively. Therefore, the amount of gas from cracked paleo oil pool in the Dingshan-Lintanchang structural belt was $G=G_{1}+G_{2}=5332 \times 10^{8} \mathrm{~m}^{3}$, which indicated presence of a rich source rock for the formation of paleo gas pool.

Table 2 Parameters for reserves calculation of Sinian paleo-traps in the Lintanchang and Dingshan structures

\begin{tabular}{cccccccccc}
\hline Parameter & \multirow{2}{*}{$A_{0}, \mathrm{~km}^{2}$} & $H, \mathrm{~m}$ & $H_{\mathrm{o}}, \mathrm{m}$ & $\Phi, \%$ & $S_{\mathrm{o}}, \%$ & Boi & $\rho, \mathrm{t} / \mathrm{m}^{3}$ & $Q, 10^{8} \mathrm{t}$ \\
Structure & & & & & & & & \\
\hline Lintanchang & 220 & 350 & 120 & 5 & 70 & 1.24 & 0.9 & 6.7 \\
Dingshan & 120 & 500 & 42 & 7.5 & 70 & 1.24 & 0.9 & 1.9
\end{tabular}

$A_{\mathrm{o}}$ : Oil-bearing area; $H$ : Oil column height; $H_{\mathrm{o}}$ : Effective reservoir thickness; $\Phi$ : Effective porosity; $S_{0}$ : Oil saturation; Boi: Oil volume factor; $\rho$ : Oil density; $Q$ : Paleo-reserves $\left(S_{0}, B o i\right.$ and $\rho$ are from Sun et al (2007))

\subsection{Formation of the Sinian paleo oil (gas) pool}

After the lower Cambrian sedimentation, the buried depth 
of the top Sinian surface (the bottom of the lower Cambrian Niutitang Formation source rocks) was about $800 \mathrm{~m}$ in the Dingshan 1 Well and $700 \mathrm{~m}$ in the Lin 1 Well, so the lower Cambrian Niutitang Formation source rocks (mudstone) were not yet mature (Fig. 5).

After the Ordovician sedimentation, the burial depth of the Sinian top surface reached about 2,000 $\mathrm{m}$ in the Dingshan 1 Well and 1,900 $\mathrm{m}$ in the Lin 1 Well. During the late Ordovician, the lower Cambrian source rocks became mature, but the main hydrocarbon generating center was located in the Dingshan structure. The first stage paleo oil pool was located in the Lintanchang and Dingshan structures.

After the Silurian sedimentation, the burial depth of the Sinian top surface reached 2,600 $\mathrm{m}$ in the Dingshan 1 Well and 2,400 $\mathrm{m}$ in the Lin 1 Well. During the DevonianCarboniferous, the source rocks in the study area went through an intermission in hydrocarbon generation. The paleo oil pool in the Dingshan structure was damaged by the Caledonian movement, whereas the pool in the Lintanchang structure was well preserved.

After the Permian sedimentation, the buried depth of the top of the Sinian reached 2,800 $\mathrm{m}$ in the Dingshan 1 Well and $2,600 \mathrm{~m}$ in the Lin 1 Well, with the early structural framework being preserved. However, the hydrocarbon generation center migrated toward the Lin 1 Well. The Lintanchang-Dingshan structural belt was high at the west and low at the east. At that time, the lower Cambrian source rocks intensely generated hydrocarbon and the Lin 1 Well located on the high point of the structure captured a large quantity of oil. The size of the two phases superimposed paleo oil pool reached up to $6.7 \times 10^{8}$ $t$ in the Lin 1 Well. The Dingshan 1 Well is located at the top of the Dingshan structure and the size of paleo oil pool reached $1.9 \times 10^{8} \mathrm{t}$ (Fig. 5).

Afterwards, the buried depth, temperature, and pressure at the Sinian top surface increased due to continuous subsidence. In the late Triassic, the buried depth of the Sinian top surface reached 4,800 $\mathrm{m}$ and the geotemperature was $170^{\circ} \mathrm{C}$. Large amounts of oil trapped in the Sinian began to crack, the pressure in the oil-gas reservoir increased further, and reached a peak during the late early Cretaceous (74 Ma). Fission track analysis of the apatite showed that the buried depth of the Sinian top surface in the Dingshan 1 Well once reached 7,060 $\mathrm{m}$, with temperature up to $220^{\circ} \mathrm{C}$. Thus a large paleo gas pool was formed from a large amount of cracked hydrocarbons. The main cap rocks (including gypsum) in the area were very good, and gypsum was a good sealing for gas diffusion. The sealing was destroyed after folding, uplifting and denudation during the Yanshan-Himalayan period. Therefore, there was a paleo gas pool because of oil cracking before the sealing was destroyed. The Lintanchang structure had a paleo gas pool of $4,154 \times 10^{8} \mathrm{~m}^{3}$ and that of the Dingshan structure was $1,178 \times 10^{8} \mathrm{~m}^{3}$. Therefore, the size of the whole paleo gas pool in the LintanchangDingshan structural belt reached about $5,300 \times 10^{8} \mathrm{~m}^{3}$ (Fig. 3(e), Fig. 5).

\subsection{Processes which destroyed the Sinian paleo gas pool}

\subsubsection{Folding, uplifting and denudation during Yanshan-} Himalayan period

(1) Trough-like fold formation

Since the early Cretaceous, the southeast Sichuan Basin had gone through important folding, uplifting and denudation periods (Lü and Xia, 2005; Hu et al, 2009). Influenced by the major stress field from southeast of the region, the strata were folded. The age of folded strata decreased from southeast to northwest, accompanied by gradually decreasing intensity of deformation. During this period, the multiple directions of N-E, E-W and S-N structures were superimposed in the southeast Sichuan Basin and the basin was finally shaped into a N-E trough-like structure, with the wide-gentle anticlines and tight-closed synclines (Fig. 1).

(2) Intense uplifting and formation of fracture systems

Fission track analysis was used as a quantitative simulation for the samples from the Dingshan-Lintanchang region, to reconstruct their thermal and tectonic uplift histories. The process of tectonic uplift and subsidence in the above area was divided into two major phases. Before the late Cretaceous, subsidence was dominant, but tectonic uplift (resulting in denudation) has been dominant since the late Cretaceous. The key period of tectonic transition from subsidence to uplift (denudation) was around $80 \mathrm{Ma}$. A geothermal gradient $30^{\circ} \mathrm{C} / 100 \mathrm{~m}$ and surface temperature $20^{\circ} \mathrm{C}$ were used for the simulation (Zhang, 1997). Middle or high-speed uplift occurred during 65-82 Ma, at a rate of 93 $\mathrm{m} / \mathrm{Ma}$, with an uplift amplitude of 1,030 m. Low-speed uplift occurred during 25-65 Ma, at a rate of $14.8 \mathrm{~m} / \mathrm{Ma}$, with an uplift amplitude of $720 \mathrm{~m}$. Moderate-speed uplift began to occur in the $25 \mathrm{Ma}$ period until present at a rate of $59.8 \mathrm{~m} / \mathrm{Ma}$ with an uplift amplitude of $1,360 \mathrm{~m}$. Therefore, since the late Cretaceous, at least 3,000 $\mathrm{m}$ of the strata have been eroded in this region. As a result of the uplift, the strata outcropping in this area are relatively old (Fig. 1) and many steep faults and fracture systems were formed, which greatly changed previous good reservoir conditions in the area. Because of tectonic movements, reservoirs were destroyed and the gas generated from the cracked crude oil escaped, so the paleo gas pool was totally destroyed.

\subsubsection{Sinian preservation conditions}

The isotopic composition of strontium in seawater is considered to be globally consistent (McArthur et al, 1992). Thus, strontium isotope measurements can be employed to trace and contrast fluid sources and interpret oil and gas preservation conditions. The following discussion on fluid sources and preservation conditions is based on analyses of samples from the Lin 1 Well.

(1) Isotopic geochemical characteristics and paleo-fluid sources

Through contrasts of the strontium isotope ratio in the host rocks and vugs, or fracture fillings of different horizons in the Lin 1 Well, the lower assemblage (Sinian to lower Palaeozoic) is characterized as follows (Fig. 6): (1) The 


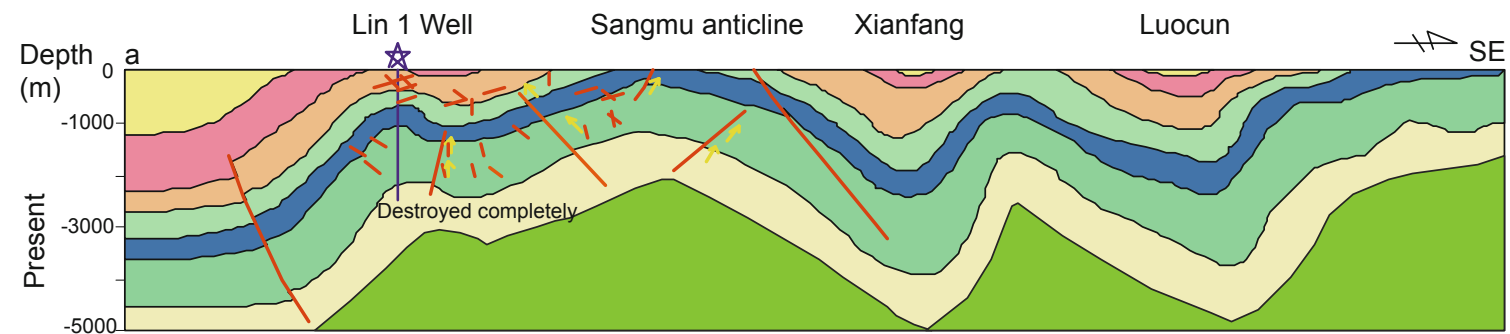

Lin 1 Well
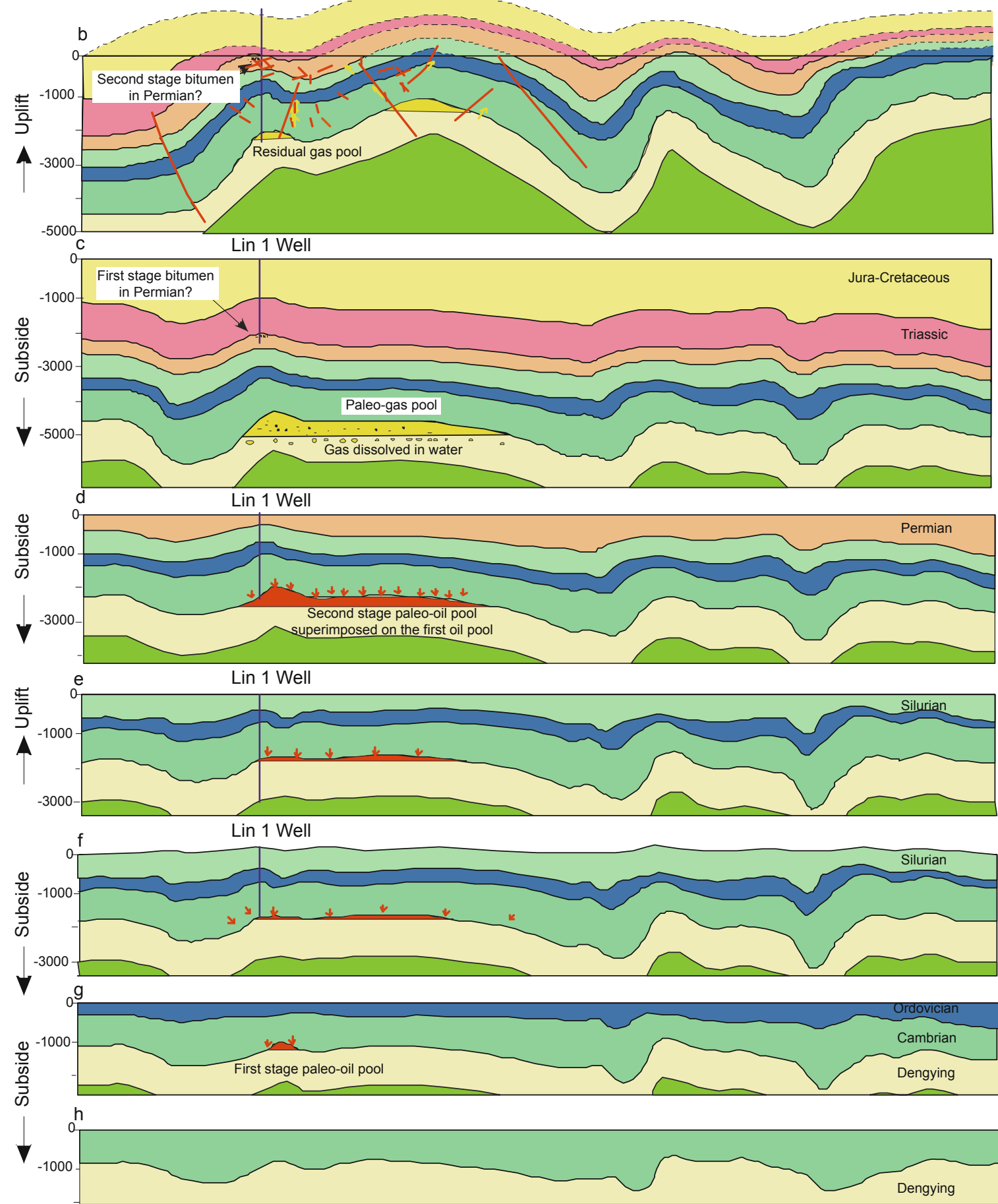

Fig. 5 Formation and destruction processes of Lintanchang paleo oil and paleo gas pools in the southeast Sichuan Basin (Based on seismic line TTBli-05-608 balanced section) (a) Present; (b) Himalayan; (c) Before Himalayan; (d) After the Permian sedimentation; (e) Before the Permian sedimentation; (f) After the Silurian sedimentation; (g) After the Ordovician sedimentation; (h) After the Sinian sedimentation 
strontium isotope ratio of host rocks and fillings is higher than that of contemporary normal seawater. (2) The strontium isotope ratio of fillings is higher than that of host carbonate rocks, but is lower than that of host clastic rocks. (3) Carbon and oxygen isotope ratios of fillings are greatly different from those of host rocks. (4) Strontium isotope ratios of adjacent horizons vary greatly. All these characteristics indicate that there were four sets of different fluid systems in the lower assemblage (Fig. 6). Fluids in the lower Silurian Shiniulan Formation and the first stage of the upper Sinian had the same source (system $\mathrm{C}_{1}$ ), whereas source rocks in the lower Silurian Longmaxi and lower Cambrian Niutitang Formation belonged to two other independent fluid systems (system A and system B). The upper Sinian fluids were extremely complex with three subsystems (system $\mathrm{C}_{1}, \mathrm{C}_{2}, \mathrm{C}_{3}$ ) (Fig. 6). Therefore, there were three major sources of fluids in the Lin 1 Well: (1) the fluid modified by re-dissolution from the lower Silurian Longmaxi Formation itself (system A); (2) the redissolution fluid of the lower Cambrian Niutitang Formation (system B); (3) the two phases of strontium-enriched fluid in the Dengying Formation (system $\mathrm{C}$ ).

(2) Loss of preservation conditions and destruction of gas pools

Fig. 6 is a trace diagram showing geochemical strontium isotope ratios in the Lin 1 Well, Dingshan 1 Well and the sections of the structural belt. Fig. 6 shows that the upper Sinian internal fluid was the most complex fluid with 2-3 subsystems no matter whether it was underground (in drilled wells) or at the surface profile. However, the overlying lower
Palaeozoic strata generally had the same fluid sources as the upper Sinian, which revealed that there was cross-formation fluid migration between the upper Sinian and the lower Palaeozoic. This also indicated that the overall preservation conditions of the upper Sinian in this structure were relatively poor. For instance, in the Dingshan-Yueping profile, the lower Cambrian cap rocks had good sealing capacity before the oil started to crack when Yanshan-Himalayan uplifting began. The upper Sinian and the overlying lower Palaeozoic had mutually independent fluid systems. The abnormal pressure in the reservoir strata in the Dengying Formation reached up to 78-86 $\mathrm{MPa}$ during oil cracking (data obtained from simulation pressure tests of fluid inclusions), approaching the breakthrough pressure of the Niutitang Formation. Furthermore, high angle faults and fracture systems were formed. The loss of sealing by the overlying argillaceous rocks and gypsum led to cross-formation fluid migration among the upper Sinian, the Ordovician and the Silurian. At the same time, the cracked gas pool in the upper Sinian was destroyed.

It can be concluded that the Cambrian gypsum and mudstone in the Dingshan and Lintanchang structural belt had a relatively good sealing capacity before and at the beginning of the oil cracking. Nevertheless, the study area had been strongly tectonically folded, uplifted and denuded since the late Cretaceous, with the upper Sinian to the lower Palaeozoic strata subaerially exposed. Thus the earlier good preservation conditions were lost and the cracked gas pools in the Dengying Formation were destroyed (Fig. 5).

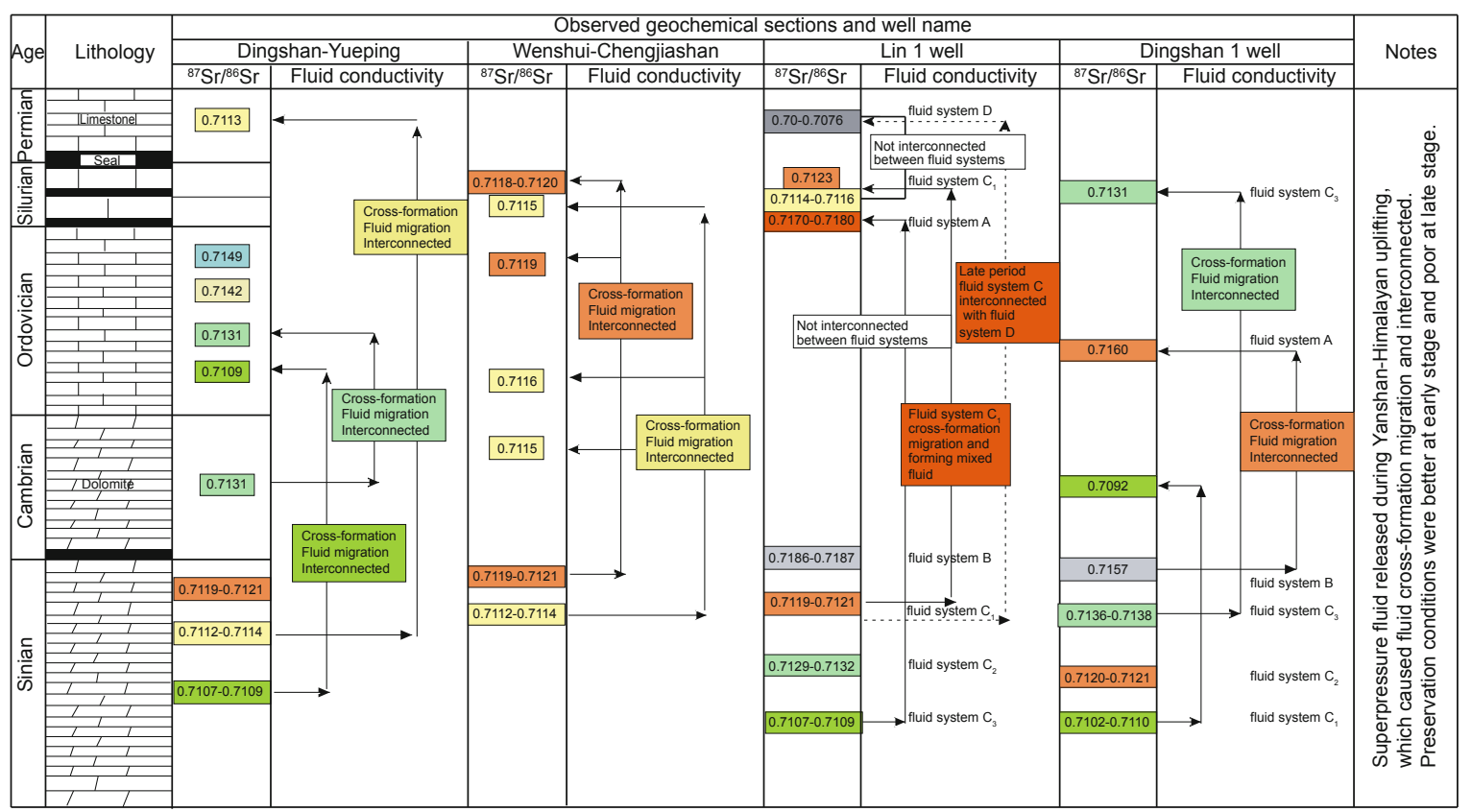

Fig. 6 Diagram showing cross-formation fluid migration from Sinian to lower Palaeozoic in the Dingshan-Lintanchang structure, southeast Sichuan Basin

\section{Discussion}

\subsection{Distribution of oil saturation in the Dengying Formation controlled by paleo-uplifts}

The bitumen content in the Dengying Formation in the
Sichuan Basin was the highest at the axis of the Caledonian Leshan-Longnüsi paleo-uplift (also called the central Sichuan uplift). The bitumen content in the Nüji Well reached $8.1 \%$ (Fig. 7). The bitumen content declined from the uplift to the depressions (e.g. Woshen 1 Well $0.4 \%$, Zishen 1 Well $1.1 \%$ ) (Wang et al, 2002). This indicated that the Caledonian 


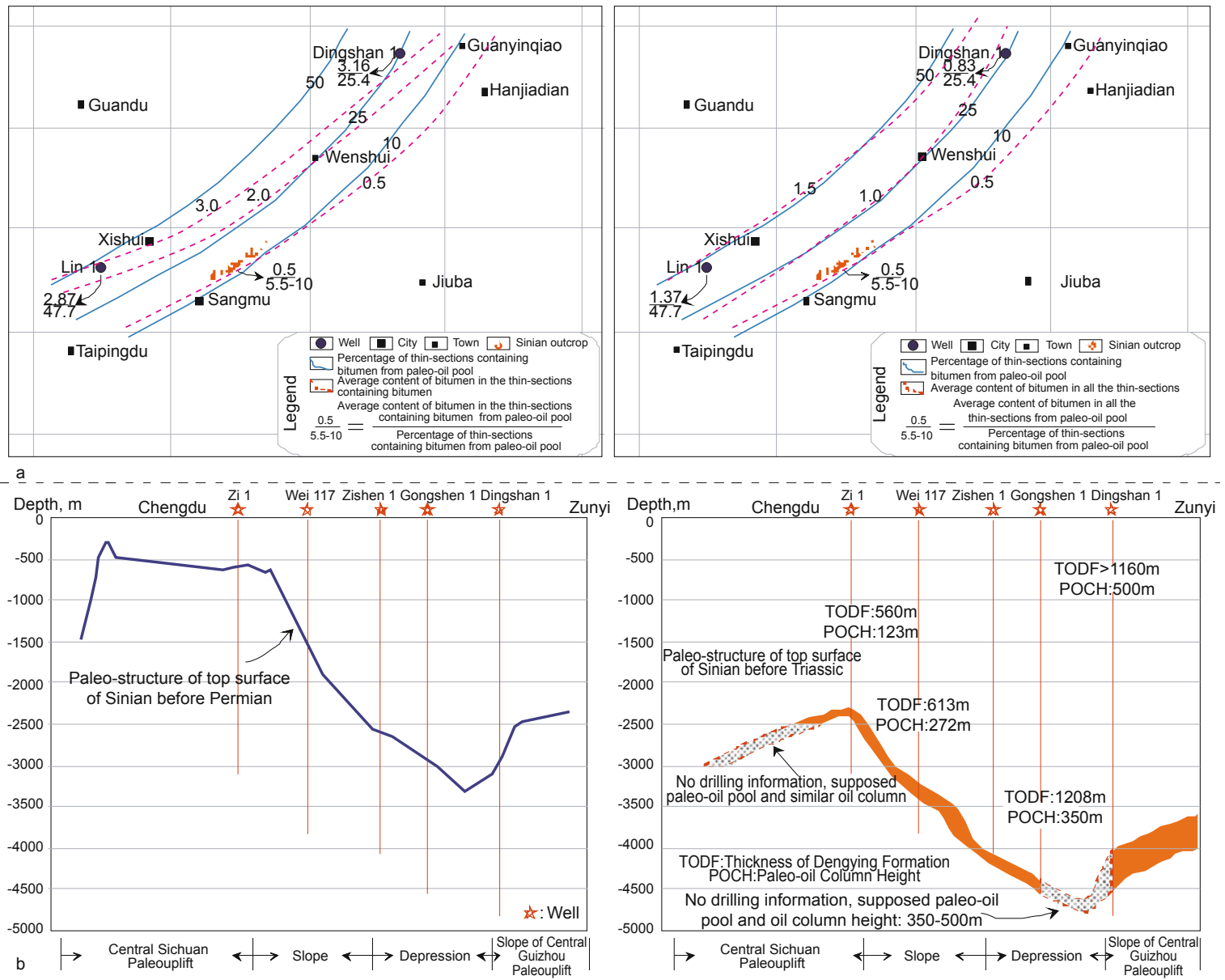

Fig. 7 Characteristics of paleo oil pools of the upper Sinian in the Sichuan Basin and its peripheral areas

(a) Plan distribution of the Dengying Formation bitumen in the paleo oil pool in the Dingshan-Lintanchang structural belt; (b) Profile of the paleo oil field from the central Sichuan paleo-uplift to the slope of central Guizhou paleo-uplift (See the well location in Fig. 8)

paleotectonic framework controlled the distribution of oil in the Dengying Formation, and that the paleo-uplift was the primary area of oil migration and accumulation.

The southeast Sichuan Basin is located in the slopedepression area of the central Guizhou paleo-uplift with the Woshen-Gongshen depression between this region and the Leshan-Longnüsi paleo-uplift. The Permian-Triassic was the most important period for the generation of hydrocarbons in the study area. Before the Triassic and the Permian, the study area was located at the northern slope of the central Guizhou paleo-uplift. During the peak of oil filling, the LintanchangDingshan belt was a local structural high on the slope of central Guizhou paleo-uplift with large quantities of oil accumulating (Fig. 7).

The bitumen content in the Dengying Formation in Lin 1 well and Dingshan 1 well was lower than that at the LeshanLongnüsi paleo-uplift (Fig. 7). The percentage of the thin sections containing bitumen in Lin 1 well and Dingshan 1 well is similar with that of the paleo-uplift. For instance, the percentage of thin sections containing bitumen inside paleo oil column in the Lin 1 Well (at least $242 \mathrm{~m}$ in height) was $47 \%$ (25\% in the Dingshan 1 Well) (Fig. 7(a)), close to that in the Woshen 1 Well located in the depression, but is higher than that in the Wei 117 Well (39\%) located on the slope.

The characteristics of the upper Sinian paleo oil pools of Jinsha Yankong, Kaiyang Yangshui (Yongshaba) and Weng'an Baidoushan (Qianchang) in the central Guizhou paleo-uplift indicate that there was an upper Sinian large paleo oil field similar to that in the Leshan-Longnüsi paleouplift (Tian et al, 2006; Zhou and Liang, 2006; Yang et al, 2008). Therefore, bitumen can be observed today in any of the Dengying Formation outcrops and well cores. There was probably an ultra-large, structure related oil-gas field in the Dengying Formation in the Sichuan Basin and its peripheral areas (Fig. 8).

\subsection{Positive correlation between oil column heights of paleo oil pools and residual thickness of the Dengying Formation}

Fig. 7(b) is the profile of the upper Sinian paleo oil field from the central Sichuan paleo-uplift (Leshan-Longnüsi paleo-uplift) to the Lintanchang-Dingshan structural belt in the southeast Sichuan Basin. It can be seen that the Dengying Formation in Zi 1 Well, Wei 117 Well (uplift area) and Gongshen 1 Well (depression area) had a residual thickness of $560 \mathrm{~m}, 613 \mathrm{~m}$ and $1,208 \mathrm{~m}$, with an oil column height of $123 \mathrm{~m}, 272 \mathrm{~m}$ and $350 \mathrm{~m}$, respectively. Also located in a depression area of the northern slope of the central Guizhou paleo-uplift, the Dengying Formation in the Dingshan 1 well was of at least $1,160 \mathrm{~m}$ thick with $500 \mathrm{~m}$ oil column height. 


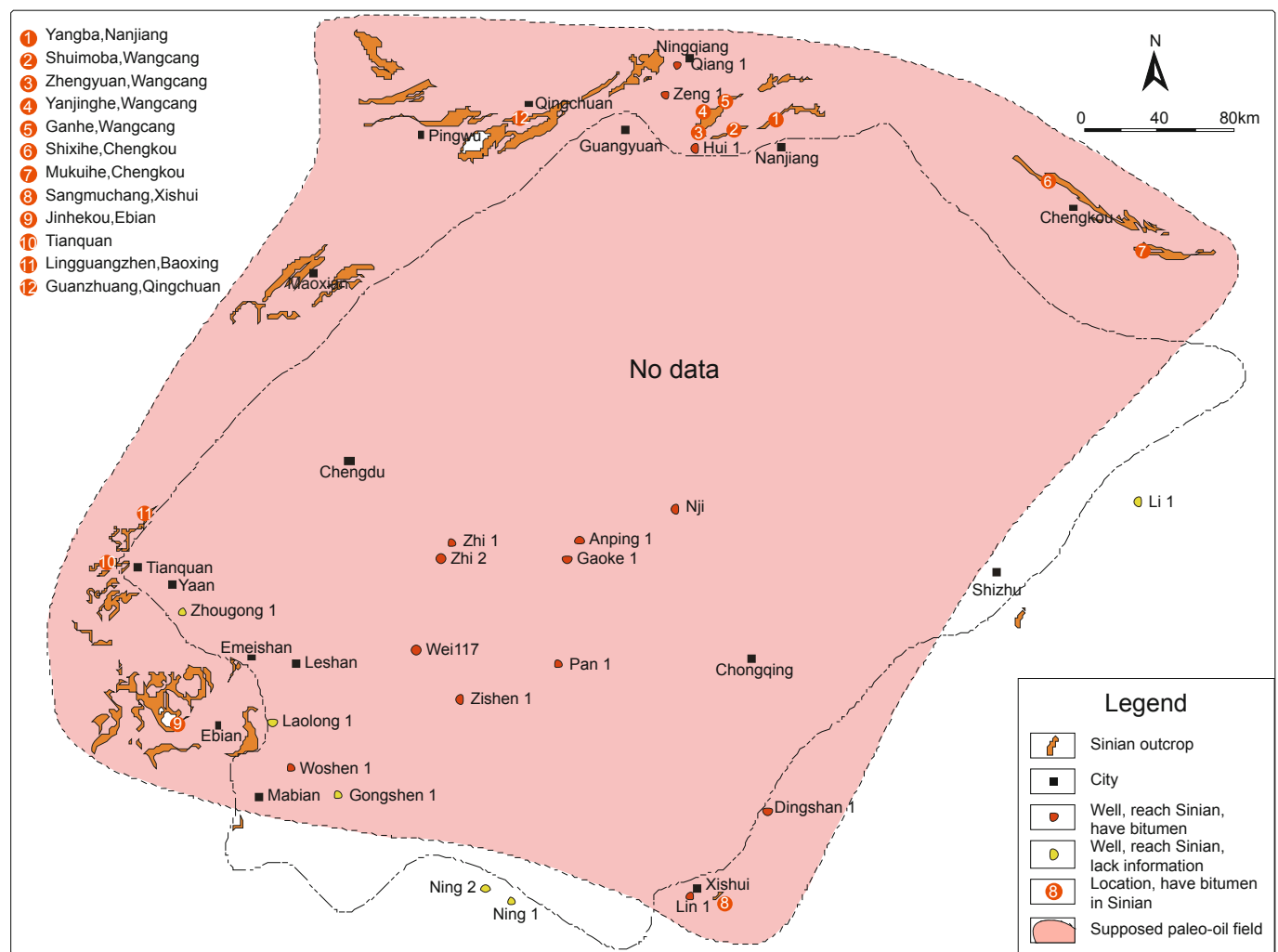

Fig. 8 Diagram showing the distribution of the ultra-large structure-lithologic oil-gas field in the upper Sinian in the Sichuan Basin and its peripheral areas

Hence, it could be concluded that bitumen content in the uplift area was high, whereas the paleo oil column height was relatively low.

In conclusion, the high content of bitumen of the Dengying Formation in the paleo-uplift areas suggested that the paleo-uplifts were the preferential areas of oil-gas migration and accumulation. The low paleo oil columns in these areas indirectly indicated that there was no unified oil-water interface in the upper Sinian paleo oil field from paleo-uplifts to slope areas. The Dengying Formation is characterized by petroleum pool formation and local hydrocarbon enrichment in the Sichuan Basin and its periphery areas.

\section{Conclusions}

1) The lower Cambrian source rocks in the DingshanLintanchang structural belt in the southeast Sichuan Basin were of medium-good quality with two excellent hydrocarbon-generating centers developed in the periphery areas. The upper Sinian dolomite (Dengying Formation) formed good reservoir rocks. The overlying cap rocks of the lower Cambrian Niutitang Formation mudstone provided satisfactory sealing capacity. Therefore, there were excellent original geologic conditions for hydrocarbon accumulation in the Dengying Formation.

2) The Dingshan-Lintanchang structural belt had a paleo oil pool with $8.6 \times 10^{8} \mathrm{t}$ oil and then a paleo gas pool with $5,300 \times 10^{8} \mathrm{~m}^{3}$ gas from cracked oil.

3) The formation and destruction processes of the Dengying Formation oil-gas pool in the DingshanLintanchang structural belt occurred in several stages. The first stage of paleo oil pool formation was maturation of the lower Cambrian source rocks during the late Ordovician. The hydrocarbon generation from the lower Cambrian source rocks stopped during the Devonian to the Carboniferous tectonic uplifting. The lower Cambrian source rocks then generated large quantities of hydrocarbons during the second stage of paleo oil pool formation, after the middle Permian deposition. The oil began to crack and the paleo gas pool was formed during the late Triassic. This paleo gas pool was damaged and reservoirs were destroyed as a result of extensive Yanshan-Himalayan folding, uplifting and denudation.

4) Residual bitumen can be found in the Dengying Formation inside the Sichuan Basin as well as in its periphery areas. It is suggested that there was an ultra-large oil-gas field formed within the Dengying Formation, with petroleum pools formed widely from local hydrocarbon enrichment in the Sichuan Basin and its periphery areas. Consequently the paleo gas pools were formed from thermal cracking of crude oil, with the pools destroyed during the Yanshan-Himalayan folding, uplifting and denudation.

\section{Acknowledgements}

This study was supported by the National Basic Research Program of China (No. 2005CB422106). We are thankful to Luba Jansa for the assistance during field studies.

\section{References}

Ao M C, Lü T Z, Hu N F, et al. Lithological features of the Dengying Formation of the Sinian in Well Dingshan 1 in south-eastern part of Sichuan province and its comparison with neighbouring strata. 
Southern China Oil \& Gas. 2006. 19(S1): 5-9 (in Chinese)

Barker C. Calculated volume and pressure changes during the thermal cracking of oil to gas in reservoirs. AAPG Bulletin. 1990. 74(8): 1254-1261

Barth T and Bjørlykke K. Organic acids from source rock maturation: generation potentials, transport mechanisms and relevance for mineral diagenesis. Applied Geochemistry. 1993. 8(4): 325-337

Cander H. Interplay of water-rock interaction efficiency, unconformities, and fluid flow in a carbonate aquifer: Floridan aquifer system. In: Unconformities and Porosity in Carbonate Strata. AAPG Memoir 1995. 63: 103-124

Dai J X. Pool-forming periods and gas sources of the Weiyuan gasfield. Petroleum Geology \& Experiment. 2003. 25(5): 473-480 (in Chinese)

Dickson J A D and Saller A H. Identification of subaerial exposure surfaces and porosity preservation in Pennsylvanian and Lower Permian shelf limestones, eastern Central Basin platform, Texas. In: Unconformities and Porosity in Carbonate Strata. AAPG Memoir. 1995. 63: 239-257

Hu Z Q, Zhu G, Liu G S, et al. The folding time of the eastern Sichuan Jura-type fold belt: evidence from unconformity. Geological Review. 2009. 55(1): 32-42 (in Chinese)

Liang D G, Guo T L, Chen J P, et al. Some progress in studies of hydrocarbon generation and accumulation in marine sedimentary regions, southern China (Part 1): Distribution of four suits of regional marine source rocks. Marine Origin Petroleum Geology. 2008. 13(2): 1-16 (in Chinese)

Liu R B, Tian J C, Wei Z H, et al. Comprehensive research on effective hydrocarbon source rocks of lower strata from the Sinian to Silurian system in the southeast area of Sichuan province. Natural Gas Geoscience. 2006. 17(6): 824-828 (in Chinese)

Liu S G, Ma Y S, Huang W M, et al. Densification process of the upper Sinian Dengying Formation, Sichuan Basin. Natural Gas Geoscience. 2007. 18(4): 485-496 (in Chinese)

Liu S G, Ma Y S, Sun W, et al. Study of the differences of Sinian natural gas pools between Weiyuan gas field and the Ziyang gas-prone area, Sichuan Basin. Acta Geologica Sinica. 2008a. 82(3): 328-337 (in Chinese)

Liu S G, Ma Y S, Wang G Z, et al. Formation and conservation mechanisms of the high-quality reservoirs in Sinian-lower Palaeozoic in the Sichuan Basin. Petroleum Geology and Recovery Efficiency. 2008b. 15(1): 1-5 (in Chinese)

Liu S G, Sun W, Li Z W, et al. Tectonic uplifting and gas pool formation since the late Cretaceous epoch, Sichuan Basin. Natural Gas Geoscience. 2008c. 19(3): 293-300 (in Chinese)

Liu S G, Wang H, Sun W, et al. Energy field adjustment and hydrocarbon phase evolution in the Sinian-Lower Paleozoic, Sichuan Basin. Journal of China University of Geosciences. 2008d. 19(6): 700-706

Lu S F, Xue H T and Zong N N. The chemical kinetic study of the oil preservation threshold. Petroleum Exploration and Development. 2002. 29(6): 1-3 (in Chinese)
Lü B F and Xia B. New knowledge about ejective structures in southeast Sichuan. Natural Gas Geoscience. 2005. 16(3): 278-282 (in Chinese)

McArthur J M, Burnett J and Hancock J M. Strontium isotopes at K/T boundary: discussion. Nature. 1992. 355(6355): 28

Meng Q R, Wang E and Hu J M. Mesozoic sedimentary evolution of the northwest Sichuan Basin: Implication for continued clockwise rotation of the South China block. Geological Society of America Bulletin. 2005. 117(3-4): 396-410

Qin J Z, Jin J C and Liu B Q. Thermal evolution patterns of organic matter abundance in various marine source rocks. Oil \& Gas Geology. 2005. 26(2): 177-184 (in Chinese)

Qin J Z, Liu B Q, Zheng L J, et al. Study of capability of hydrocarbon generation and expulsion from marine carbonate source rocks. Oil \& Gas Geology. 2006. 27(3): 348-355 (in Chinese)

Qin J Z, Tengeer and Fu X D. Study of forming condition on marine excellent source rocks and its evaluation. Petroleum Geology \& Experiment. 2009. 31(4): 366-372 (in Chinese)

Sun W, Liu S G, Han K Y, et al. The petroleum geological condition and exploration prospect analysis in the Sinian, Sichuan Basin. Petroleum Geology \& Experiment. 2009. 31(4): 350-355 (in Chinese)

Sun W, Liu S G, Ma Y S, et al. Determination and quantitative simulation of gas pool formation processes of Sinian cracked gas in the Weiyuan-Ziyang area, Sichuan Basin. Acta Geologica Sinica. 2007. 81(8): 1153-1159 (in Chinese)

Sun W, Liu S G, Wang G Z, et al. Petroleum formed condition and process research for the Sinian to Lower Paleozoic in the Dingshan structure in the southeast of the Sichuan Basin. Geological Science and Technology Information. 2010. 29(1): 49-55 (in Chinese)

Tian H Q, Guo T L, Hu D F, et al. Marine lower assemblage and exploration prospects of the central Guizhou Uplift and its adjacent areas. Journal of Palaeogeography. 2006. 8(4): 509-518 (in Chinese)

Wagner P D, Tasker D R and Wahlman G P. Reservoir degradation and compartmentalization below subaerial unconformities: limestone examples from west Texas, China, and Oman. In: Unconformities and Porosity in Carbonate Strata. AAPG Memoir. 1995. 63: 177-194

Wang Z C, Zhao W Z, Zhang L, et al. Tectonic Sequence and Natural Gas Exploration of the Sichuan Basin. Beijing: Geological Publishing House. 2002. 149-156 (in Chinese)

Wu S C. Introduction of Petroleum Resources Assessment-from "Digital Earth" to "Digital Reservoir" (Second Edition). Beijing: Petroleum Industry Press. 2005. 268-273 (in Chinese)

Yang C Q, Yue Q L and Cao B. Natural gas exploration prospect and direction in the Lower Paleozoic in the Qianzhong Uplift and its periphery. Geoscience. 2008. 22(4): 558-566 (in Chinese)

Zhang Y C. Prototype Analysis of Petroliferous Basins in China. Nanjing: Nanjing University Publishing House. 1997. 13-23 (in Chinese)

Zhou M H and Liang Q Y. Petroleum geological conditions of the lower assemblage in the Qianzhong Uplift and peripheral regions. Marine Origin Petroleum Geology. 2006. 11(2): 17-24 (in Chinese)

(Edited by Hao Jie) 